\title{
The Effect of Body Posture on Brain Glymphatic Transport
}

\author{
Hedok Lee, ${ }^{1,2 *}$ Lulu Xie, ${ }^{5 *}$ Mei Yu, ${ }^{1}$ Hongyi Kang, ${ }^{5}$ Tian Feng, ${ }^{3}$ Rashid Deane, ${ }^{\circledR}$ Jean Logan, ${ }^{4}$ Maiken Nedergaard, ${ }^{5}$ \\ and ${ }^{(D)}$ Helene Benveniste ${ }^{1,2}$ \\ ${ }^{1}$ Department of Anesthesiology, ${ }^{2}$ Department of Radiology, and ${ }^{3}$ Department of Applied Mathematics and Statistics, Stony Brook University, Stony Brook, \\ New York 11794, ${ }^{4}$ Department of Radiology, New York University Langone Medical Center, New York, New York 10016, and ${ }^{5}$ Center for Translational \\ Neuromedicine, University of Rochester, Rochester, New York 14627
}

The glymphatic pathway expedites clearance of waste, including soluble amyloid $\beta(\mathrm{A} \beta)$ from the brain. Transport through this pathway is controlled by the brain's arousal level because, during sleep or anesthesia, the brain's interstitial space volume expands (compared with wakefulness), resulting in faster waste removal. Humans, as well as animals, exhibit different body postures during sleep, which may also affect waste removal. Therefore, not only the level of consciousness, but also body posture, might affect CSF-interstitial fluid (ISF) exchange efficiency. We used dynamic-contrast-enhanced MRI and kinetic modeling to quantify CSF-ISF exchange rates in anesthetized rodents' brains in supine, prone, or lateral positions. To validate the MRI data and to assess specifically the influence of body posture on clearance of $\mathrm{A} \beta$, we used fluorescence microscopy and radioactive tracers, respectively. The analysis showed that glymphatic transport was most efficient in the lateral position compared with the supine or prone positions. In the prone position, in which the rat's head was in the most upright position (mimicking posture during the awake state), transport was characterized by "retention" of the tracer, slower clearance, and more CSF efflux along larger caliber cervical vessels. The optical imaging and radiotracer studies confirmed that glymphatic transport and $\mathrm{A} \beta$ clearance were superior in the lateral and supine positions. We propose that the most popular sleep posture (lateral) has evolved to optimize waste removal during sleep and that posture must be considered in diagnostic imaging procedures developed in the future to assess CSF-ISF transport in humans.

Key words: brain; CSF; posture; sleep; unconsciousness; waste removal

Significance Statement

The rodent brain removes waste better during sleep or anesthesia compared with the awake state. Animals exhibit different body posture during the awake and sleep states, which might affect the brain's waste removal efficiency. We investigated the influence of body posture on brainwide transport of inert tracers of anesthetized rodents. The major finding of our study was that waste, including $\mathrm{A} \beta$, removal was most efficient in the lateral position (compared with the prone position), which mimics the natural resting/sleeping position of rodents. Although our finding awaits testing in humans, we speculate that the lateral position during sleep has advantage with regard to the removal of waste products including $A \beta$, because clinical studies have shown that sleep drives $\mathrm{A} \beta$ clearance from the brain.

\section{Introduction}

In recent studies, we reported on the brainwide paravascular pathway, in which a large proportion of subarachnoid CSF circulates through the brain parenchyma via para-arterial spaces, exchanges with the interstitial fluid (ISF), and exits along paravenous pathways (Iliff et al., 2012). This so-called "glymphatic"

\footnotetext{
Received April 27, 2015; revised June 4, 2015; accepted June 29, 2015.

Author contributions: H.L., L.X., M.N., and H.B. designed research; H.L., L.X., M.Y., H.K., R.D., M.N., and H.B. performed research; H.L., L.X., M.Y., R.D., J.L., and H.B. contributed unpublished reagents/analytic tools; H.L., L.X., H.K., T.F., R.D., J.L., and H.B. analyzed data; H.L., M.N., and H.B. wrote the paper.

This work was supported by "FBRI" and the National Institutes of Health (Grant R01 AG048769 to H.B. and M.N.) and the Department of Anesthesiology, Stony Brook Medicine. We thank Gina DiCarlo from Department of Anesthesiology, Stony Brook Medicine, for editorial assistance.

The authors declare no competing financial interests.
}

pathway facilitates the clearance of interstitial waste from the brain parenchyma (Nedergaard, 2013). Subsequent studies showed that glymphatic transport is controlled by the brain's arousal level (Xie et al., 2013). During sleep or anesthesia, the brain interstitial space volume expands significantly compared with the awake state (Xie et al., 2013). This finding is in agreement with other studies demonstrating synaptic plasticity and downselection of synapses in association with sleep (Bushey et al., 2011; Cirelli and Tononi, 2015). The enlarged interstitial space volume

\section{*H.L. and L.X. contributed equally to this work.}

Correspondence should be addressed to Helene Benveniste, MD, PhD, Department of Anesthesiology, Stony Brook Medicine, Stony Brook, NY 11794. E-mail: Helene.Benveniste@stonybrookmedicine.edu. DOI:10.1523/JNEUROSCI.1625-15.2015

Copyright $\odot 2015$ the authors $\quad 0270-6474 / 15 / 3511034-11 \$ 15.00 / 0$ 
A
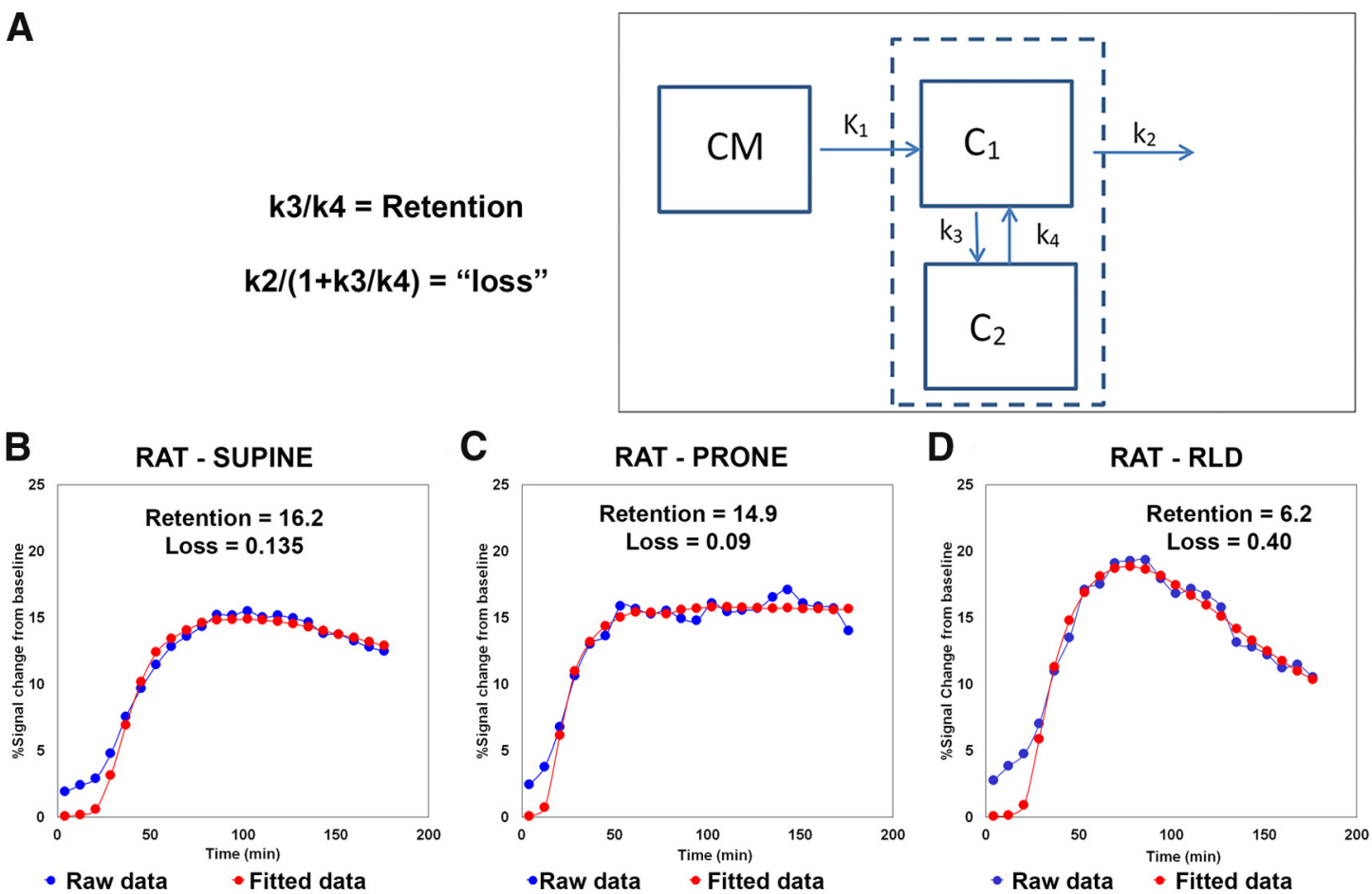

Figure 1. A, Two-compartment model used for characterizing transport of Gd-DTPA contrast into and out of the brain. The compartment model use the defined TSCS from the CM and whole brain (excluding CSF spaces) to calculate retention and loss. Compartments $C_{1}$ and $C_{2}$ are assumed to occupy the same space. The main input $\left(K_{1}\right)$ is represented by TSC from the $C M$. Tracer "retention" can be described as $k_{3} / k_{4}$ and "loss" (or clearance) as the parameter $k_{2} /\left(1+k_{3} / k_{4}\right)$. Examples of raw data (blue) and fitted data derived from the two-compartment model (red) from representative rats in supine ( $\boldsymbol{B})$, prone $(\boldsymbol{C})$, and RLD (D) positions. As can be seen, the calculated parameter for "retention" is highest for the rat in prone position and "loss" is most pronounced in the rat positioned in RLD.

during deep-wave sleep lowers the overall resistance to paravascular inflow, resulting in a sharp increase in CSF-ISF exchange and convective transport of waste solutes toward paravascular spaces surrounding large caliber cerebral veins for ultimate clearance via cervical lymphatic vessels (Xie et al., 2013).

Humans, as well as animals, exhibit different body posture during the awake and sleep states. Therefore, not only arousal level, but also body posture, might affect the brain's waste removal efficiency. For example, cerebral hemodynamics and intracranial pressures are highly influenced by body posture (Schneider et al., 1993; Brosnan et al., 2002; Kose and Hatipoglu, 2012) and this in turn could affect glymphatic pathway transport. Characterizing the effect of different body postures on glymphatic pathway transport may prove important for understanding waste removal during various physiological states, including sleep, and may serve as a future guide for optimizing diagnostic testing related to this CSF-ISF transport system. Here, we use dynamic-contrast-enhanced MRI (Iliff et al., 2013a) to track glymphatic transport in rats in the supine, prone, and lateral decubitus positions and use kinetic modeling to capture both tracer retention and clearance in real time. The MRI data was validated by executing similar positional experiments in rodents using quantitative optical imaging and fluorescently tagged tracers used previously to assess glymphatic transport (Iliff et al., 2012).

\section{Materials and Methods}

Procedures. All animal procedures were approved by the Institutional Animal Care and Use Committee and all studies were conducted in accordance with the United States Public Health Service's Policy on $\mathrm{Hu}-$ mane Care and Use of Laboratory Animals. Adult Sprague Dawley female rats were used for the MRI studies and adult C56BL6/J mice were used for the optical and radiolabeled clearance studies.

Anesthesia and monitoring. Rats were induced with 3\% isoflurane in $100 \% \mathrm{O}_{2}$ and, at the time of loss of the righting reflex, they received an intraperitoneal injection of ketamine $(80-100 \mathrm{mg} / \mathrm{kg}) / x y l a z i n e ~(5-10$ $\mathrm{mg} / \mathrm{kg}$ ). The rats were allowed to breathe spontaneously and body temperature was strictly controlled at $37 \pm 1^{\circ} \mathrm{C}$ using a heating pad. Physiological parameters including heart rate, respiratory rate, and oxygen saturation were monitored continuously. Mice were anesthetized with ketamine $(0.12 \mathrm{mg} / \mathrm{g}$, i.p. $)$ and xylaxzine $(0.01 \mathrm{mg} / \mathrm{g}$, i.p.). Mouse body temperature was also strictly controlled at $37 \pm 1^{\circ} \mathrm{C}$ using heated air.

Cisterna magna catheter. Anesthetized rats were placed in a stereotaxic frame and the neck gently flexed $30-40^{\circ}$. The atlanto-occipital membrane was exposed and, via a small durotomy, a polyethylene catheter was inserted into the subarachnoid cisterna magna (CM) space as described previously (Iliff et al., 2013a). Mice were fixed in a stereotaxic frame and the posterior atlanto-occipital membrane overlying the cisterna magna was surgically exposed. A $30 \mathrm{Ga}$ needle was implanted into the $\mathrm{CM}$ and glued to the skull with dental cement. The open end of the needle was inserted into a piece of polyethylene tubing, which was sealed by cauterization (Xie et al., 2013; Kress et al., 2014).

Intrathecal contrast administration. For all MRI experiments, we administered Gd-DTPA (Magnevist) to rats as described previously (Iliff et al., 2013a). To ensure that an isobaric intrathecal solution of Gd-DTPA was used, we applied a refractometer (T3-NE Desktop Refractometer; Atago); a 1:40 dilution of Gd-DTPA in sterile water was determined to have a density of approximate $1.005 \mathrm{~g} / \mathrm{ml}$, which is isobaric with respect to CSF (CSF specific gravity $=1.004-1.007 \mathrm{~g} / \mathrm{ml}$ ). For CSF tracer experiments in mice, a small molecular weight (MW; Texas Red-conjugated dextran) and a large MW tracer (FITC-conjugated dextran, $2000 \mathrm{kDa}$ ) were first constituted in artificial CSF at a concentration of $0.5 \%$ and then infused together into the CSF via the CM cannula at a rate of $2 \mu \mathrm{l} / \mathrm{min}$ for a period of $5 \mathrm{~min}$ (10 $\mu \mathrm{l}$ total volume) using a syringe pump (Harvard 
Apparatus). To visualize the penetration of fluorescent CSF tracers into the brain parenchyma ex vivo, anesthetized animals were transcardially perfusion fixed with $4 \%$ paraformaldehyde (PFA) 30 min after the start of infusion. Brains were then dissected and postfixed in 4\% PFA for $24 \mathrm{~h}$ before being sliced into $100 \mu \mathrm{m}$ coronal sections using a vibratome and mounted using PROLONG antifade gold with DAPI (Invitrogen). Tracer movement along perivascular spaces and permeation of the brain parenchyma were visualized in ex vivo studies by conventional fluorescence microscopy and confocal laser scanning microscopy.

Glymphatic transport MRI imaging. MRI was conducted on a $9.4 \mathrm{~T} / 20$ MRI instrument controlled by Paravision 5.0 software (Bruker) as described previously (Iliff et al., 2013a). The rats were divided into three groups based on their body position during MRI imaging: the supine,

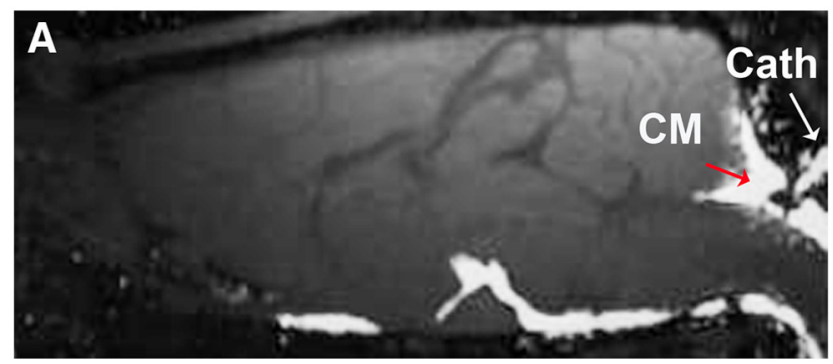

\section{B CISTERNAMAGNATACs}

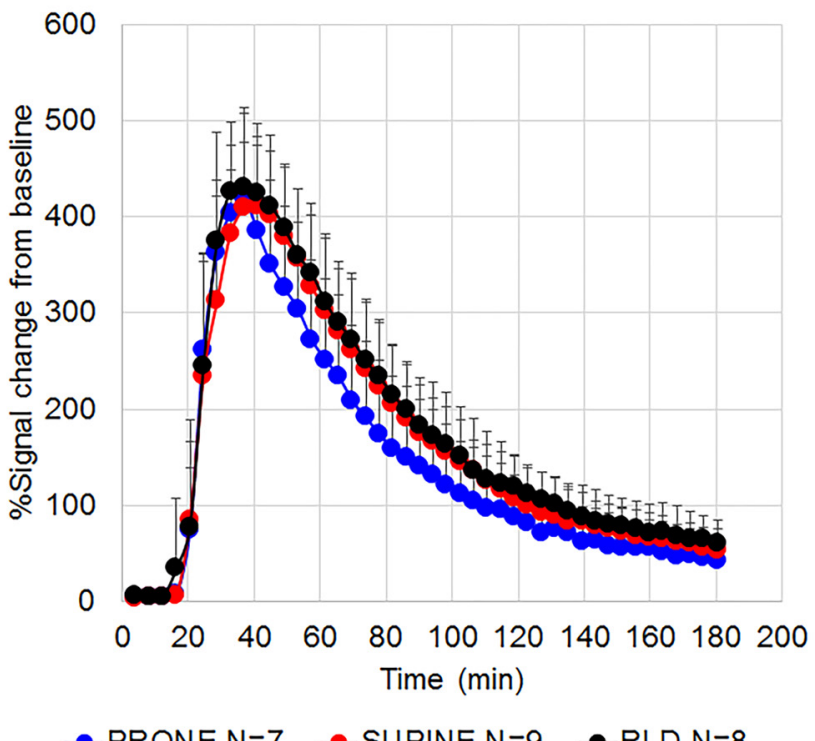

Figure 2. TSCs from the CM of rats in different body positions. $\boldsymbol{A}$, T1-weighted MRI of rat brain at the level of the $C M \sim 30$ min after infusion of Gd-DTPA. Note that the CM catheter can be appreciated as a straight, high-signal-intensity line (white arrow). $\boldsymbol{B}$, Average TSCs associated with infusion of Gd-DTPA into the CM for rats positioned in prone (blue, $n=7$ ), supine (red, $n=9)$, and RLD $(n=8)$ body posture. Data are presented as mean \pm SD. As can be observed, the TSCs from the three groups are identical and statistical analysis confirmed this statement (Table 1). right lateral decubitus (RLD), and prone positions. In the supine and RLD positions, the RF surface coil was placed underneath the head of the rat. For the rats in prone position, we developed a home-built, MRIcompatible head holder, which accommodated the RF coil on the top of the skull. After localizer anatomical scout scans, a 3D T1-weighted FLASH sequence $\left[\mathrm{TR}=15 \mathrm{~ms}, \mathrm{TE}=3.4 \mathrm{~ms}\right.$, flip angle $15^{\circ}, \mathrm{NA}=1$, FOV $=3.0 \times 3.0 \times 3.2 \mathrm{~cm}$, scanning time $=4 \min 5 \mathrm{~s}$, acquisition matrix size of $256 \times 128 \times 128$ interpolated to $256 \times 256 \times 256$ yielding an image resolution of $0.12 \times 0.12 \times 0.13 \mathrm{~mm}$ ] were acquired in the coronal plane. The scanning protocol consisted of three baseline scans followed by intrathecal administration of Gd-DTPA ( $20 \mu \mathrm{l}$ infused over $20 \mathrm{~min}$ ) while imaging acquisitions continued for $2-3 \mathrm{~h}$.

MRI imaging processing and analysis. General MRI image processing consisted of head motion correction, intensity normalization, smoothing, and voxel-by-voxel conversion to percentage of baseline signal using SPM8 as described previously (Iliff et al., 2013a). From each of the parametric dynamic MRI images, "time-signal curves" (TSCs) of Gd-DTPAinduced contrast changes derived from the CM were extracted using PMOD software (version 3.5). From the CM TSCs, the following parameters were calculated: area-under-curve (AUC) over the first $60 \mathrm{~min}$ $\left(\mathrm{AUC}_{0-60}\right)$, AUC over $120 \mathrm{~min}\left(\mathrm{AUC}_{0-120}\right)$, peak magnitude, and timeto-peak. For the CSF efflux calculations, TSCs from each of the anatomical ROIs were extracted and the AUCs over 120 min $\left(\mathrm{AUC}_{0-120}\right)$ were derived.

To calculate distribution volume $\left(V_{\mathrm{T}}\right)$ of Gd-DTPA (representing uptake/transport via the glymphatic pathway), the TSCs from the CM (representing the main "input" function to the brain), from the whole brain, and from four brain regions (cerebellum, hippocampus, midbrain, and orbitofrontal cortex) were extracted from each rat and the Logan plot (Logan et al., 1990; Logan et al., 2001) was applied using kinetic modeling PMOD software (version 3.5).

Modeling kinetic glymphatic transport patterns of Gd-DTPA. We used two-compartmental kinetic analysis to model the glymphatic movement of Gd-DTPA contrast through brain tissue using the parametric MRI images. The TSCs from the CM (main input) and TSCs from the whole brain (excluding CSF spaces) from each rat were extracted and the four rate constants $\left(K_{1}\right.$ and $\left.k_{2}-k_{4}\right)$ were calculated from the curve fits using PMOD software (Fig. 1). Figure $1 A$ shows the two-compartment model with the constant controlling influx from the $\mathrm{CM}\left(K_{1}\right)$ and the efflux constant $k_{2}$,we have introduced a second compartment $\left(C_{2}\right)$ with transfer constants $k_{3}$ and $k_{4}$. In this case, the space of compartment $2\left(C_{2}\right)$ is considered to be the same as $C_{1}$ and serves to "slow" the movement of contrast particles through the brain. Therefore, we can describe tracer "retention" as $k_{3} / k_{4}$ and "loss" as the parameter $k_{2} /\left(1+k_{3} / k_{4}\right)$ as described previously (Koeppe et al., 1991). Although these assumptions may not be strictly true in the setting of contrast-enhanced MRI, it is known that many noncompartment systems can be fit with exponentials (Rescigno and Bocchialini, 1991). The potential limitation of this approach relates to the physical interpretation of the "voxelwise percent signal change" derived from the Gd-DTPA contrast enhancement. Standard dynamic-contrast-enhanced MRI kinetic models typically convert contrast enhanced image intensities into tissue contrast concentrations (Tofts, 1997). In this study, "percent signal changes" were interpreted as a surrogate marker for the contrast concentrations even though these two entities are not strictly linear (Tofts, 1997). Despite these flaws, the twocompartment model used here to analyze the data is applied with the assumption that the potential errors would be approximately the same

Table 1. Comparison of parameters derived from CM TSCs

\begin{tabular}{|c|c|c|c|c|c|c|c|}
\hline \multirow[b]{2}{*}{ Parameter } & \multicolumn{2}{|c|}{ Prone $(n=7)$} & \multicolumn{2}{|c|}{ Supine $(n=9)$} & \multicolumn{2}{|c|}{$\mathrm{RLD}(n=8)$} & \multirow[b]{2}{*}{$p$-value } \\
\hline & Mean & SD & Mean & SD & Mean & SD & \\
\hline $\mathrm{AUC}_{0-60}\left(\%\right.$ signal change $\left.{ }^{*} 60 \mathrm{~min}\right)$ & 13534 & 2780 & 14217 & 3714 & 15103 & 2604 & 0.63 \\
\hline $\mathrm{AUC}_{0-120}(\%$ signal change $* 120 \mathrm{~min})$ & 23417 & 6493 & 25399 & 6757 & 26764 & 4995 & 0.41 \\
\hline Peak (\% signal change from baseline) & 437 & 78 & 429 & 95 & 454 & 49 & 0.79 \\
\hline Time-to-peak $(\min )^{*}$ & 33 & $(33,36)$ & 41 & $(37,45)$ & 37 & $(32,38)$ & 0.15 \\
\hline
\end{tabular}

*The median ( $1^{\text {st }}$ quartile, $3^{\text {rd }}$ quartile) rather than the mean (SD) was used for "time-to-peak."

$p<0.05$ was considered statistically significant. No significant group differences were found. 
across studies and groups. Figure $1, B-D$, are examples of the raw TSC data and the corresponding fitted curves using the two-compartment model from representative rats of each positional group.

Quantitative imaging analysis of fluorescent CSF tracer accumulation. Tracer penetration into the brain and spinal cord was evaluated by epifluorescence microscopy as described previously (Xie et al., 2013; Kress et al., 2014). In brief, eight brain sections per animal were imaged and analyzed by a blinded investigator using an Olympus fluorescence microscope under $4 \times$ objective power to generate whole-slice montages (using the Virtual Slice module of Microlucida software; MicroBrightfield) subsequently quantified using ImageJ software.

Radiolabeled tracer clearance. To evaluate the rates of interstitial fluid and solute clearance from the brain, radiolabeled tracer $\left({ }^{125} \mathrm{I}-\mathrm{A} \beta 1-40\right)$ was injected stereotaxically into the brain parenchyma. A $30 \mathrm{Ga}$ needle was implanted into the right frontal cortex of anesthetized 10- to 12-week-old mice with the coordinates of the cannula tip at $0.7 \mathrm{~mm}$ anterior and $3.0 \mathrm{~mm}$ lateral to the bregma and $1.3 \mathrm{~mm}$ below the surface of the brain. Animals were allowed to recover after surgery and the experiments were performed 12-24 $\mathrm{h}$ after the guide tube cannulation. Clearance of $\mathrm{A} \beta$ was studied under three postures: prone, lateral, and supine. In each mouse, a small volume of mock CSF $(0.5 \mu \mathrm{l})$ containing ${ }^{125}$ I-labeled $\mathrm{A} \beta$ (10 nM monomer) ${ }^{125} \mathrm{I}-\mathrm{A} \beta 1-40$ was injected into brain ISF over $5 \mathrm{~min}$. After $30 \mathrm{~min}$, the brain was removed and prepared for radioactivity analysis TCA analyses of $A \beta .{ }^{125} \mathrm{I}$ radioactivity was determined using a gamma counter. For calculations of clearance rates, the percentage of radioactivity remaining in the brain after microinjection was determined as percentage recovery in brain = $100 \times(\mathrm{Nb} / \mathrm{Ni})$, where $\mathrm{Nb}$ is the radioactivity remaining in the brain at the end of the experiment and $\mathrm{Ni}$ is the radioactivity injected into the brain ISF; that is, the c.p.m. for the TCA-precipitable ${ }^{125}$ I radioactivity. The percentage clearance of ${ }^{125} \mathrm{I}-\mathrm{A} \beta$ was calculated from the total, as 100 - brain recovery.

Statistical analysis. For the comparison of parameters derived from TSCs extracted from the CM and CSF efflux pathways, one-way ANOVA was used to investigate whether the parameters were different between the three groups. Normality was examined via the Shapiro-Wilk test. Welch's ANOVA was used if the variance homogeneity condition did not hold. Tukey's range test, which accounts for multiple comparisons, was used as a post hoc analysis for ANOVA to compare each pair of two groups ( $t$ test/ Welch's $t$ test with FDR correction was used instead as post hoc test if homogeneity of variance did not hold for ANOVA). The Kruskal-Wallis (K-W) test was used to compare the time-to-peak parameters between the groups instead of ANOVA because time is an ordinal rather than a continuous variable. The Wilcoxon rank-sum test with FDR correction was used as post hoc test for the K-W test. The parameters "retention" and "loss" between the three groups were also analyzed with $\mathrm{K}-\mathrm{W}$ test with a post hoc Wilcoxon rank-sum test. Differences in physiological parameters between the three groups of rats over time were analyzed by first calculating the coefficient of variation $(\mathrm{CV})$ of the heart rate and respiratory rate for each rat over time. Subsequently, a K-W test was used to compare the median heart rate CV and median respiratory rate CV between the three groups. A post hoc Wilcoxon rank-sum test was used to identify group differences. For the fluorescent CSF-tracer analysis and radiolabeled tracer clearances studies, a one-way ANOVA with Bonferroni post hoc test was used to analyze the difference between the three groups. All analyses were conducted using SAS version 9.3 and XLSTAT (Addinsoft, version 2014). $p<0.05$ was considered statistically significant.

\section{Results}

\section{Physiological parameters in rats during MRI studies}

It was demonstrated previously that pulsatility drives glymphatic influx (Iliff et al., 2013b) and that respiratory rate influences intracranial pressure as well as CSF flow (Grubb et al., 1974; Grant et al., 1989; Newell et al., 1996; Schneider et al., 1998). Furthermore, recent studies in humans show that the most important driver of CSF flow is inspiratory force (Dreha-Kulaczewski et al., 2015). Therefore, differences in physiological parameters such as heart rate and respiratory rate caused by changes in body posture might also explain the changes in glymphatic transport. Physio- logical data including respiratory and heart rates obtained over the course of the study from the three groups demonstrated no statistical differences (results not shown). However, overall heart rate variability was less in RLD rats compared with those in the supine and prone positions.

\section{Effect of posture on brain tissue transport of Gd-DTPA}

We first confirmed that the amount of Gd-DTPA delivered into the $\mathrm{CM}$ was the same for each of the three postures tested. Figure 2 shows that the delivered Gd-DTPA ( $20 \mu \mathrm{l}$ of isobaric infused over $20 \mathrm{~min}$ ) into CSF, via the CM, produced consistent signal changes in all rats regardless of body position. We have previously established that this infusion rate does not trigger increases in intracranial pressure (Yang et al., 2013). Quantification of the parameters derived from the CM TSCs are shown in Table 1 and confirms that CM tracer "input" is the same for all groups. Using CM TSCs as input function, the brain uptake/transport of the Gd-DTPA tracer was characterized by the total tissue distribution volume $\left(V_{\mathrm{T}}\right)$ of Gd-DTPA using the Logan plot (PMOD kinetic modeling module version 3.5). The analysis showed that the average whole-brain Gd-DTPA $V_{\mathrm{T}}$ was significantly different across the three groups $\left(\mathrm{K}-\mathrm{W}\right.$ test, $\chi^{2}$ statistic $\left.=8.62, \mathrm{DF}=2, p<0.02\right)$. In the post hoc test, $V_{\mathrm{T}}$ was found to be significantly lower in prone rats compared with supine (Wilcoxon rank-sum test, $p=$ 0.024 ) and RLD rats (Wilcoxon rank-sum test, $p=0.018$ ). Figure 3 shows the positional differences in regional brain uptake in the cerebellum, midbrain, hippocampus, and orbital frontal cortex. Statistical analysis showed that regional uptake of Gd-DTPA in the cerebellum midbrain and hippocampus was dependent on posture and statistically significantly different across the groups (Fig. 3). Post hoc analysis revealed that prone rats had lower uptake compared with RLD rats in the cerebellum (Wilcoxon ranksum test, $p=0.042$ ), hippocampus (Wilcoxon rank-sum test, $p=0.042$ ), and midbrain (Wilcoxon rank-sum test, $p=0.027$ ).

\section{Effect of posture on glymphatic transport kinetics}

Compartmental analysis was used to characterize the kinetic glymphatic transport patterns in the different body positions (Fig. 1). Some assumptions of compartmental analysis are that the tracer/contrast is distributed uniformly throughout the compartment and that the tracer/contrast particles all have the same probability of being transferred. In other words, the rate constants represent the fractional transfer rates from one compartment to another. The solution to the differential equations is the convolution of a response function (consisting of a sum of exponentials) with an input function. Table 2 shows the median "retention" and "loss" calculated from the rate constants derived from the two-compartment model fitting from the three groups; and, as can be seen from Table 2 , retention (K-W test, $\chi^{2}$ statistic $=9.59, \mathrm{DF}=2, p=0.008)$ and loss $\left(\mathrm{K}-\mathrm{W}\right.$ test, $\chi^{2}$ statistic $=$ $7.70, \mathrm{DF}=2, p=0.021$ ) defined by the rate constants are significantly different between the positional groups. In the post hoc test, retention and loss were both significantly different between the prone and RLD groups. Specifically, the prone animals exhibited more tissue retention of the tracer over time compared with RLD animals (Wilcoxon rank-sum test, $p=0.006$ ). In addition, loss of the tracer over time was significantly less in the prone rats compared with RLD animals (Wilcoxon rank-sum test, $p=$ 0.008). Tracer retention in the prone rats also trended to be higher than supine rats (Wilcoxon rank-sum test, $p=0.068$ ). In summary, analysis of the whole-brain TSCs showed that brain tissue transport of Gd-DTPA appears to be most efficient in ro- 
A
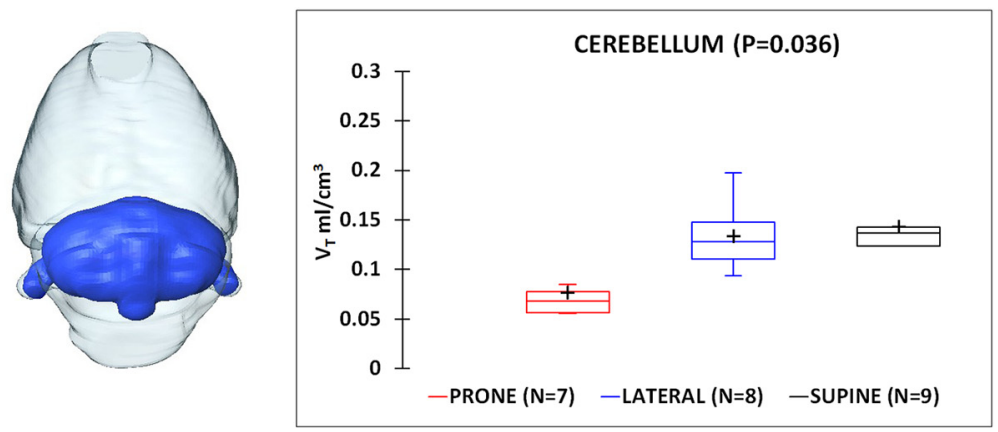

B
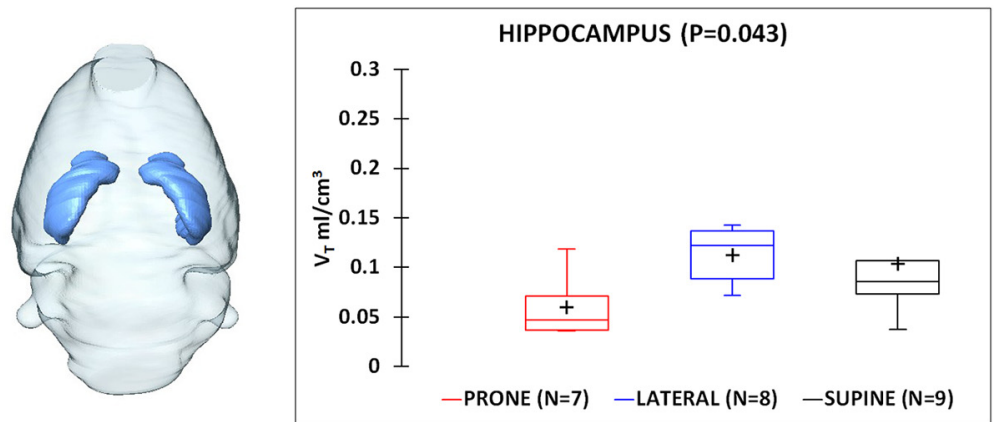

C
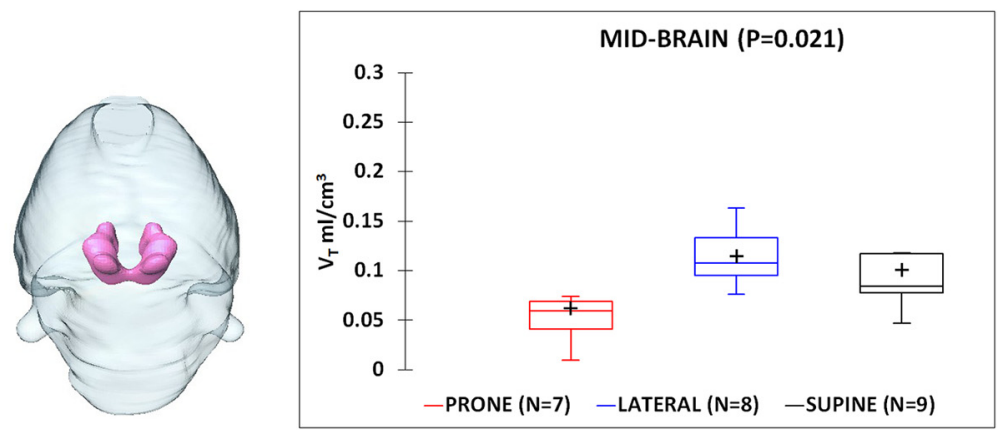

D
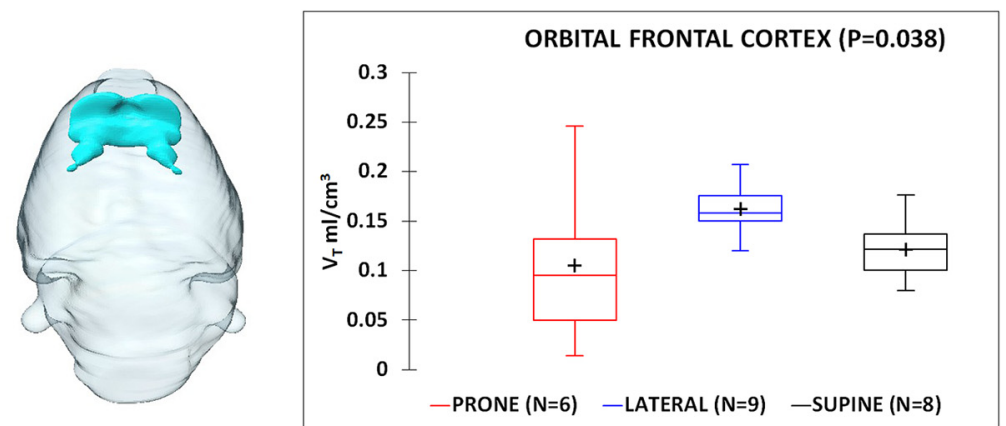

Figure 3. Effect of posture on brain transport of Gd-DTPA. Gd-DTPA transport/uptake for the cerebellum $(\boldsymbol{A})$, hippocampus $(\boldsymbol{B})$, midbrain $\left(\boldsymbol{C}\right.$, and orbital frontal cortex $(\boldsymbol{D})$ represented by $V_{\mathrm{T}}$ derived from executing the Logan plot. The data are presented as boxand-whisker plots (median, first quartile, third quartile, minimum, and maximum values); red: prone; blue: lateral, and black: supine. For each box-and-whisker plot, the corresponding 3D volume rendered brain region is shown: cerebellum (dark blue), hippocampus (light blue), midbrain (pink), and orbitofrontal cortices (turquoise). The $V_{T} s$ were compared between the three groups [prone $\left(n=7^{*}\right)$, lateral $(n=8)$, supine $(n=9)$ ] via the $\mathrm{K}-\mathrm{W}$ test, which demonstrated positional dependence $(p<0.05)$ for all brain regions. The Wilcoxon rank-sum test was performed as a post hoc test to compare $V_{T}$ s between each of two groups with correction for multiple comparisons via FDR. This analysis showed that rats in prone position had significantly lower uptake of Gd-DTPA in the cerebellum ( $p<$ $0.05)$, hippocampus $(p<0.05)$, and midbrain $(p<0.03)$ compared with rats in the RLD position. *For the orbital frontal cortex, one rat's time activity curve in the prone group failed in the Logan-plot-fitting routine for estimation of $V_{T}$ and was excluded from the group analysis.

\section{Effect of posture on alternate CSF} efflux pathways

Given that the overall delivery of GdDTPA from the CM into the brain was proven to be similar across the three groups (Fig. 1, Table 1) and whole-brain glymphatic transport/uptake $\left(V_{\mathrm{T}}\right)$ (as well as regional uptake in the cerebellum, hippocampus, and midbrain) was reduced in the prone compared with the RLD position (Fig. 2), we hypothesized that this might be attributed to alternate CSF efflux patterns in prone rats. For example, if a fraction of CSF is exiting "prematurely" along cranial nerves and/or neck large vessels from the CM when the brain is in a more upright position, this could explain why less CSF from the CM enters the brain of rats in prone position compared with other body positions. To test this hypothesis, we compared transport of Gd-DTPA associated with key CSF efflux pathways between the three body positions. The key ROIs for CSF efflux were identified on the anatomical MRIs and included the auditory nerve-cochlea complex (Fig. $4 A-E$ ), point of exit of the vagus $(\mathrm{X})$ nerve (Fig. $4 A, B, D)$, area along the superior sagittal (SS) sinus (Fig. 4H,I), and space along the internal carotid arteries (ICA; Fig. $4 A, F, G)$. To enhance anatomical delineation of bony structures in the area of the tympanic cavity, a small series of rats were scanned by CT (Fig. 4E). As can be seen on the CT images, part of the pathway of the ICA is hidden in the bony carotid canal (Fig. 4E). The field of view of the 3D T1weighted MRIs typically included the ICA and external carotid artery at the point of bifurcation (Fig. 4G,J). Nevertheless, on the T1-weighted MRIs, the exact anatomical identification of vessels on the neck was not optimized for this purpose, although blood (in vessels with fast flow) will appear brighter than other adjacent structures and it is not possible with certainty to identify the anatomical structure that support CSF efflux along the ICA. However, our previous studies have shown that fluorescently tagged CSF tracers enter cervical lymph vessels and that this pathway constitutes an important drainage path for biomarkers of traumatic brain injury (Plog et al., 2015).

Figure 5 shows the average TSCs obtained from the different efflux pathways of rats in the three body positions, as well as the location of the corresponding anatomical ROIs. As can be observed, the

dents positioned in RLD compared with the other body positions. The term "efficient" used here refers to less "retention" and superior "loss" as defined by the two-compartment model compared with the other two body positions.
TSCs are very different between the efflux pathways. For example, TSCs extracted along the SS sinus (Fig. 5A-C) and the acoustic nerve/cochlea (Fig. 5D-F) are characterized by a steady increase over time. In contrast, TSCs associated with the vagus 
Table 2. Comparison of kinetic parameters derived from the whole-brain twocompartment analysis

\begin{tabular}{lllll}
\hline Kinetic & Supine $(n=9)$ & Prone $\left(n=6^{*}\right)$ & $\operatorname{RLD}(n=8)$ & p-value \\
parameter &
\end{tabular}

Retention $=(\mathrm{k} 3 / \mathrm{k} 4) \quad 10.70(9.88,12.50) \quad 14.98(12.23,16.53) \quad 6.86(6.28,9.47) \quad 0.008$

Loss $=k 2 /(1+k 3 / k 4) \quad 0.23(0.13,0.26) \quad 0.14(0.09,0.21) \quad 0.31(0.23,0.40) \quad 0.021$

Data are presented as median ( $1^{\text {st }}$ quartile, $3^{\text {rd }}$ quartile) for each group.

* One rat in the prone group was excluded from analysis due to two-compartmental fitting failure of the whole-brain TSCs for unknown reasons.

nerve are characterized by a peak (Fig. 5G). Further, transport of Gd-DTPA along the ICA was most pronounced in rats positioned prone compared with the two other positions and irregular over time (Fig. $5 J$ ). Table 3 shows the quantification and the statistical analysis of the parameters derived from the TSCs of each of the exit points examined. First, it is evident that, for a given body position, efflux of CSF associated with the vagus nerve is the most prominent efflux pathway over time compared with the other routes (Fig. 5G, Table 3). Post hoc analysis of group differences revealed that the total time-weighted efflux (as measured by $\mathrm{AUC}_{0-120}$ ) associated with the SS sinus, acoustic nerve/cochlea, and the vagus nerve was found to be independent of body position (Table 3). However, efflux along the ICA was different in the prone position compared with the two other body positions ( $\mathrm{Ta}$ ble 3). Post hoc statistical analysis revealed that total ICA efflux was more pronounced in rats in prone compared with RLD ( $t$ test for independent groups, $p=0.027$ ).

\section{Effect of posture on glymphatic activity through alternative approaches}

Because, like all other methodologies, contrast-enhanced MRI has its limitations, we next sought to further characterize the importance of posture on glymphatic influx and clearance using complementary optical imaging approaches. To extend the analysis to include another species, we used adult mice $(\mathrm{C} 57 \mathrm{BL} / 6)$ rather than rats. Two fluorescent CSF tracers (small MW Texas Red-conjugated dextran, MW 3 kDa; large MW FITC-conjugated dextran, MW 2000 kDa) were slowly coinfused into the subarachnoid CSF of the CM. Thirty minutes after the start of CSF tracer infusion, animals were perfusion fixed, the brains and whole spinal cords were taken out, the brains sliced, and tracer influx of the brain and spinal cord was evaluated by whole-slice two-channel fluorescence imaging (Fig. 6A, B). We then compared the prone, supine, and lateral positions. As we reported before, $2000 \mathrm{kDa}$ tracer was restrained along the paravascular space, whereas the $3 \mathrm{kDa}$ tracer dispersed broadly within the brain parenchyma (Iliff et al., 2012). CSF tracer influx in the supine and lateral position was significantly increased compared with the prone position (Fig. $6 B,{ }^{*} p<0.05$ vs prone, one-way ANOVA, $F=8.438$, DF $=$ $2,17)$. Representative images shown in Figure $6 B$ demonstrated that, in the supine and lateral positions, CSF tracer influx was enhanced compared with the prone position (Fig. $6 B$ ). The effect of posture on glymphatic clearance was also quantified by injecting the radiolabeled tracer ${ }^{125} \mathrm{I}-\mathrm{A} \beta$ (MW $4.3 \mathrm{kDa}$ ) into cortex. The brains were harvested $30 \mathrm{~min}$ later and the remaining tracer determined by scintillation counting. The analysis showed that glymphatic clearance is more efficient in lateral and supine than in the prone position (Fig. $6 C,{ }^{*} p<0.05$ vs prone, one-way ANOVA, $\left.F=5.321, \mathrm{DF}=2,17\right)$. We evaluated previously glymphatic influx of CSF tracers in both rats and mice (Iliff et al., 2012; Iliff et al., 2013a). We speculate that the subtle differences we observed between the mouse and the rat model with regard to the supine versus the prone positions may be related to the minor species differences.
Next, we evaluated the effect of posture on spinal cord CSF influx. Interestingly, CSF tracer accumulation was several-fold higher in spinal cord than in brain. This was true for all positions studied. The prone position was associated with significantly more CSF tracer in spinal cord than the other two positions studied (Fig. $6 D,{ }^{\star} p<0.05$ vs prone, one-way ANOVA). Therefore, CSF tracer accumulation in spinal cord was an inverse function of brain CSF accumulation in the three different positions studied, suggesting that a large fraction of CSF does not flow into the brain but instead enters the spinal cord. In summary, this analysis using optical imaging techniques confirmed the MRI analysis of the effect of posture on glymphatic activity and extended the observations to demonstrate an inverse relationship between CSF influx into brain versus spinal cord.

\section{Discussion}

We investigated the influence of body posture on brainwide glymphatic transport using MRI and paramagnetic Gd-DTPA administered into the CSF of anesthetized rats. The major finding of our study is that glymphatic transport, CSF-ISF exchange in the brain, is most efficient when rats are in RLD position compared with the prone and supine positions. Less "efficient" CSF-ISF exchange is represented by more "retention" secondary to slower clearance of Gd-DTPA, as seen in the prone rats compared with RLD rats. Quantitative image analysis of fluorescently tagged tracers and radiolabeled tracers in mice confirmed the results of the MRI analysis in rats and showed that the reduced CSF influx into the brain in the prone position was paralleled by increased CSF influx into spinal cord, as well as efflux along the vagus nerve and neck vasculature. The key conclusion is that, when rats or mice are in the prone position with their head in a more upright posture, the overall CSF-ISF exchange (and clearance of Ab) is less compared with supine and lateral positions.

One of the most intriguing findings of our study was that glymphatic transport was most efficient in the recumbent, lateral position, which closely mimics the natural resting/sleeping position of rats (Datta and Hobson, 2000). In mice, the lateral and the supine position were both superior to the prone position (Fig. 6). During natural, deep sleep, rats assume a reclining, curled posture with eyes closed (Datta and Hobson, 2000). Other mammals, including dogs, cats, and even elephants (Tobler, 1992), can also sleep in a recumbent (lateral) position; although animals in the wild have sleep behaviors adapted for survival and therefore have different sleep patterns compared with humans (e.g., shorter time in deep sleep and some mammals even sleep with their eyes open). In humans, studies have documented that body posture during sleep favors the lateral position (De Koninck et al., 1983). During normal sleep cycles, humans and rodents change posture several times (De Koninck et al., 1992). In our study, we did not simulate shifts in postural changes during sleep due to experimental constraints. We showed previously that glymphatic transport changes rapidly from the sleeping to the awake state (Xie et al., 2013); however, it is as yet unknown whether a rapid body posture change during sleep (e.g., lateral to prone) would also rapidly affect glymphatic transport or clearance of waste material including $\mathrm{A} \beta$. We speculate that the level of arousal is likely to change with a spontaneous shift in body position during sleep and that this could affect glymphatic transport-at least transiently. Clearly, more investigations of these important and intriguing questions are warranted to further understand the short-term and long-term impact of body position during sleep on brainwide waste removal. 

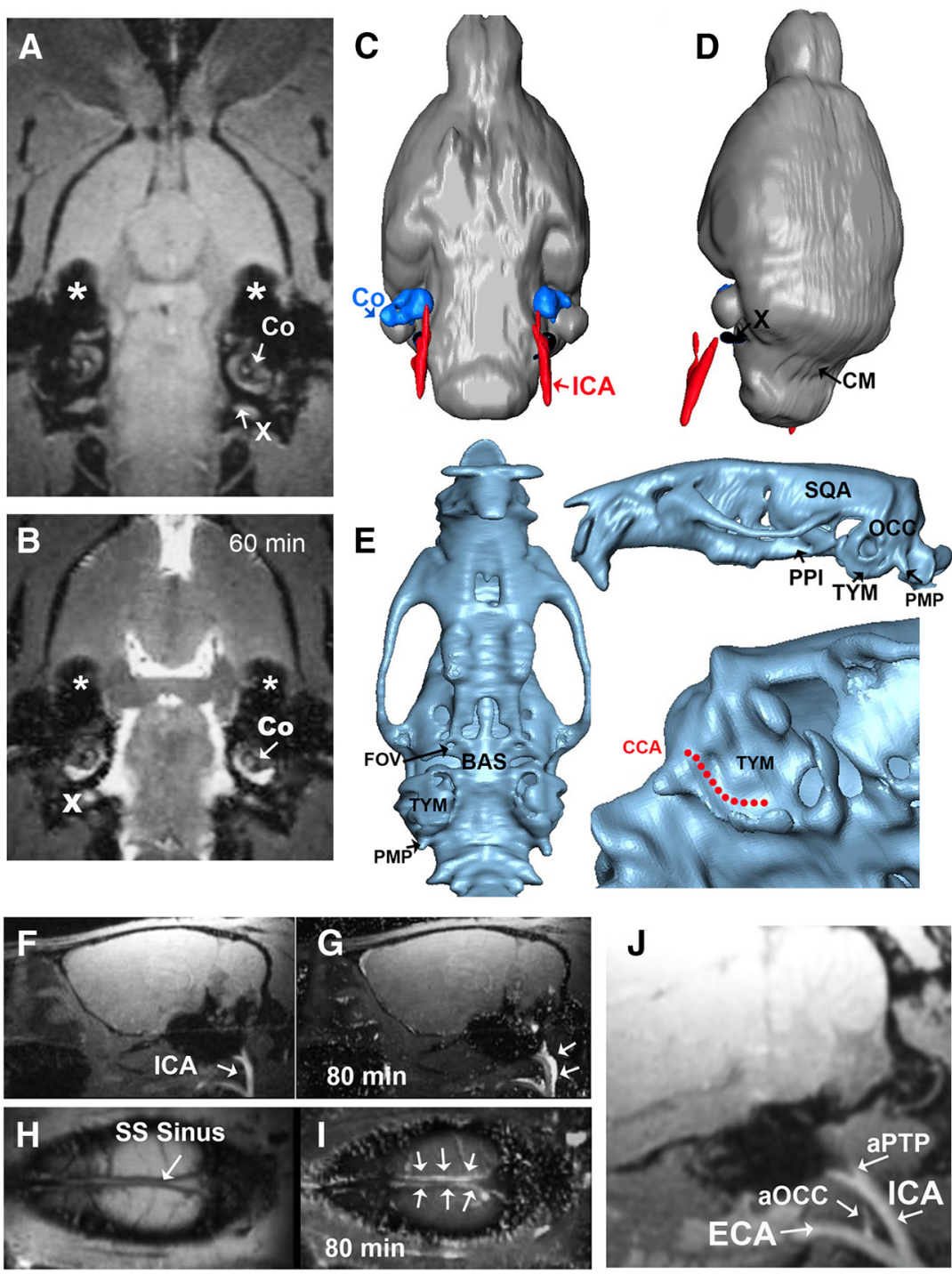

Figure 4. Anatomical key points of interestfor Gd-DTPA efflux. Horizontal sections from T1-weighted MRIs at the level of the cochlea from rat brain before $(\boldsymbol{A})$ and after $(\boldsymbol{B})$ infusion of Gd-DTPA. The cochlea ( $(0)$ can be easily identified on the T1-weighted anatomical MRIs because it is shaped like a snail shell $(\boldsymbol{A})$. The vagus nerve exits together with the glossopharyngeal (IX) nerve from the medulla oblongata below the vestibulocochlear nerve (VIII); the large nerve believed to be the vagus nerve is marked "X." Note that part of the anatomy is obscured by susceptibility artifacts (dark spots marked by * in $\boldsymbol{A}$ and $\boldsymbol{B}$ ). When contrast is infused into the CM, Gd-DTPA transport can be detected as an increase in signal intensity on the T1-weighted MRIs (brightness in $\boldsymbol{B}$ ), which can be seen surrounding the cochlea 60 min after infusion start. (At later time points contrast is also seen inside the cochlea.) The exit points of the vagal nerve are also associated with Gd-DTPA contrast $(\boldsymbol{B}) . C, D, 3 D$ surface-rendered whole brains from a rat illustrating the spatial positions of the $C M$, cochlea ( $(0$, blue), vagus nerve $(X$, black), and ICA (red). Only part of the ICA can be identified because its passage is partly obscured on the MRIs due to susceptibility artifacts and bony structures. $E$, 3 D surface-rendered images of the cranium of a rat head acquired by $C T$ to delineate all cranial components. The cranium is clearly visualized, including the squamosal (SQA), occipital (OCC), basis-phenoid (BAS), tympanic (TYM), pterygoid (PPI), paramastoid processes (PMP), and the foramen ovale (FOV). The temporal-mandibular joint (data not shown) and part of the PPI are causing the susceptibility artifacts on the MRIs obscuring the ICA as it enters the skull. Furthermore, part of the ICA runs through the bony carotid canal (CCA) shown as a dashed red line (E). F, G, Sagittal T1-weighted MRIs of a rat head at the level of the ICA shown before $(\boldsymbol{F})$ and 80 min after $(\boldsymbol{G})$ infusion of Gd-DTPA. The Gd-DTPA-induced signal changes appear as a bright signal that follow a well defined path along the ICA (sometimes along the ECA as well). $\boldsymbol{H}, \boldsymbol{I}$, Horizontal sections of T1-weighted MRIs from a rathead at the level of the $S S$ sinus before $(\boldsymbol{H})$ and 80 min after $(\boldsymbol{I})$ infusion of Gd-DTPA into the $C M$. TheSS sinus appears as a dark line in the middle of the two hemispheres (arrow, $\boldsymbol{H}$ ) and, after infusion of contrast, areas adjacent to the SS sinus appear bright (arrows, I).J, Sagittal section from T1-weighted MRI before infusion of contrast at the level of the ICA and ECA showing more detail with regard to branching vessels including the occipital artery (aOCC) arising from the ECA and the pterygopalatine artery (aPTP) arising from the ICA.

Body position is also known to influence breathing patterns in the sleeping state (De Koninck et al., 1983; Rehder, 1998). In our study, all rodents were anesthetized with a mix of ketamine and xylazine, which is known to have the fewest respiratory depres- sant effects compared with other anesthetics (Schwenke and Cragg, 2004). We did not observe any differences in respiratory rates between the groups of rats, but blood gases were not measured so it is not possible to elaborate further. However, we speculate that lower respiratory effort could reduce vascular pulsatility and vascular resistance (Czosnyka et al., 1996). More studies will be needed to characterize physiological and glymphatic transport relationships during sleep.

An important consideration is why glymphatic transport improves when placing the anesthetized rats in the RLD position compared with the other positions. The answer is likely not simple, but rather a function of complex physiological adjustments to different head and body positions (including stretch on the nerves and vessels on the neck). For example, even minor compression of the vena cava may reduce cardiac stroke volume (Martin-Du Pan et al., 2004). When patients were placed in the prone position, one study found that slight thoracic compression of venous return volume decreased stroke volume, with little impact on the heart rate (Brightman, 1965a, 1965b). The reduction in stroke volume will reduce arterial pulsatility, which is an important driver of glymphatic influx (Iliff et al., 2013b). In our study, we intentionally did not make adjustments for relieving the abdomen; therefore, venous return may have been lower in prone compared with the other body positions. In fact, it would be expected that overall sympathetic tone in the prone position would be higher as a natural response to the decrease in cardiac stroke volume from compression of venous return (Martin-Du Pan et al., 2004). Because norepinephrine is a potent inhibitor of glymphatic influx, an increase in sympathetic tone might have contributed to the reduction in glymphatic influx in the prone position (Xie et al., 2013). Moreover, immunohistochemical analysis has revealed that cervical lymph vessels are surrounded by a dense network of sympathetic and parasympathetic projections, suggesting direct autonomic control of lymphatic drainage (Mignini et al., 2012). It has also been shown that sympathetic tone is lower concomitantly with an increase in vagal tone in the right rather than in the left lateral position (Kuo et al., 2000). One possible reason for the advantage of RLD position is that the heart is positioned higher when lying on the right side. The slight elevation of the heart facilitating pumping of blood and at the greater venous return may increase cardiac stroke volume; in turn, the sympathetic tone is reduced, possibly improving glymphatic influx. 

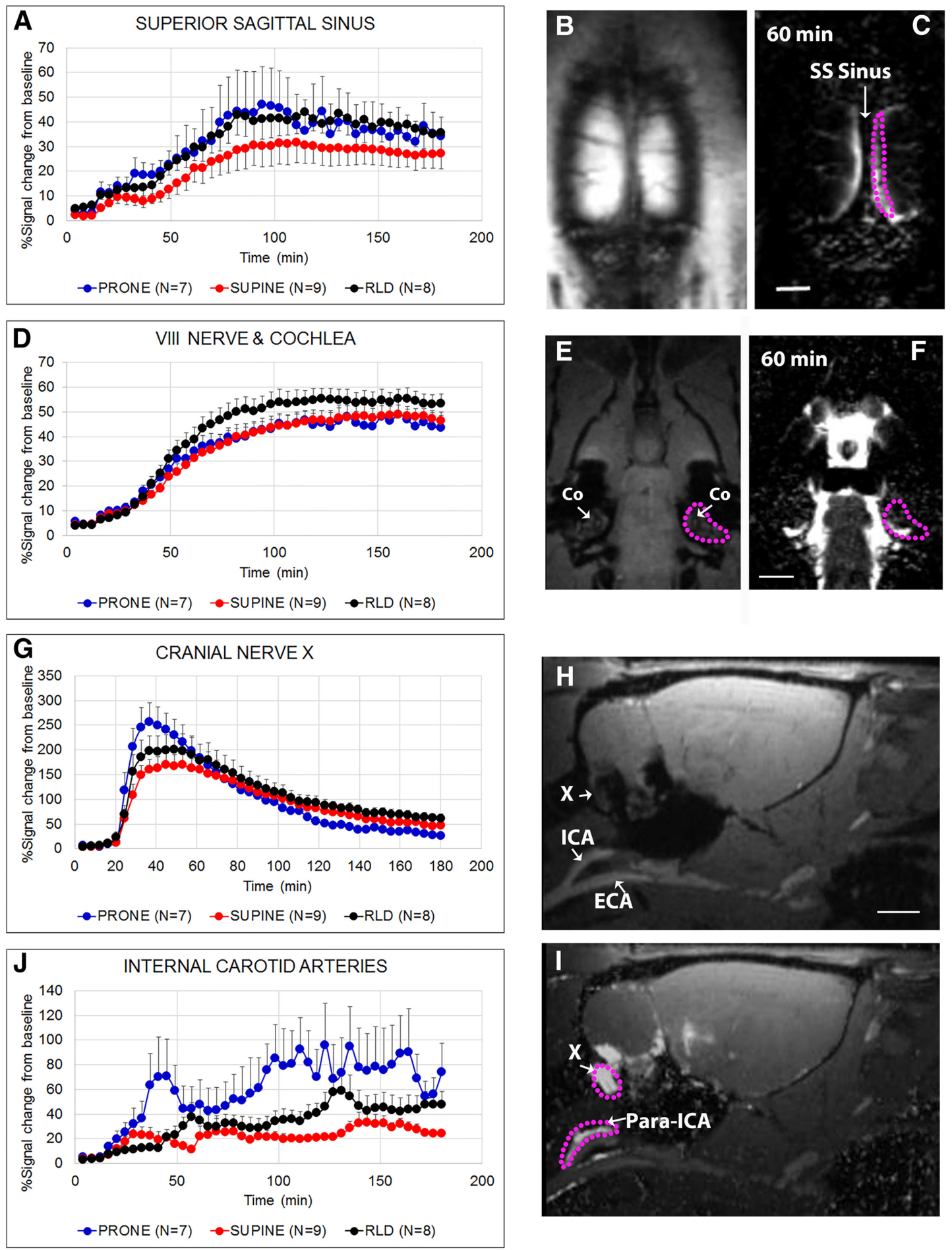

Figure 5. Analysis of the effect of posture on efflux of Gd-DTPA. Average TSCs obtained from anatomical areas associated with efflux of Gd-DTPA from the three different groups (prone, $n=7 ;$; supine, $n=$ 9; Iateral, $n=8$ ). The kinetics of the TSCs are different and dependent on anatomical point of interest. $A$, TSCs extracted from with areas along the SS sagittal sinus are characterized by a steady increase over time. $B, C$, Anatomical landmarks and illustration of the ROI measured along the SS sinus. Note that the SS sinus itself appears dark on the T1-weighted MRIs. Scale bars in B and C, 2 mm. D, TSCs extracted from the ROl-associated acoustic - cochlea complex (anatomical position illustrated in $\boldsymbol{E}$ and $\boldsymbol{F}$; scale bar, $3 \mathrm{~mm}$ ) are also characterized by a steady increase over time. $\boldsymbol{G}$, TSCs associated with the vagus (Xth) nerve are characterized by a peak. $\boldsymbol{H}, \boldsymbol{I}$, Position of the vagus nerve $(X)$ on a T1-weighted MRI in the sagittal plane at the level of the ICA and external carotid artery (ECA) before $(\boldsymbol{H})$ and after $(\boldsymbol{I})$ Gd-DTPA administration. Note that the path of the Xnerve appears to be toward the ICA; the ROl associated with the vagal nerve is also indicated. Scale bar, $3 \mathrm{~mm}$.J, TSCs derived from the areas along the ICA are characterized by a steady but variable signal change rising over time. An example of a ROI associated with this signal is shown in I. In general, CSF efflux associated with the vagus nerve was more pronounced compared with the other efflux pathways (G). Rats in prone position appear to have the largest amount of Gd-DTPA exiting along the ICA compared with the two other body positions $(J)$.

Head position during sleep is important in several disease states. For example, sudden infant death occurs most commonly in the prone position and it is therefore recommended that infants sleep in the supine position (Dwyer and Ponsonby, 2009).
Sleep position also affects the frequencies of sleep apnea episodes in patients with obstructive sleep apnea (van Kesteren et al., 2011). Both sudden infant death and sleep apnea have been linked to either autonomic instability or increased sympathetic 
A

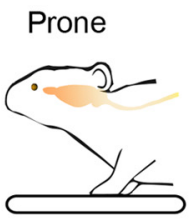

B
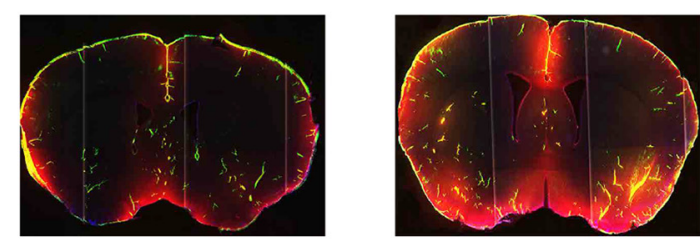

- Texas red - 3KD PITC - 2000KD

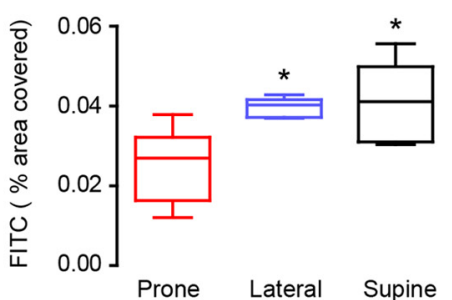

C

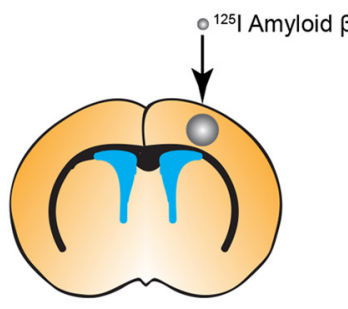

D Prone Lateral
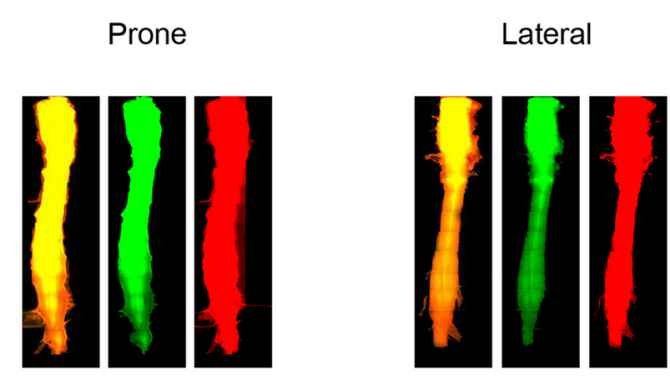
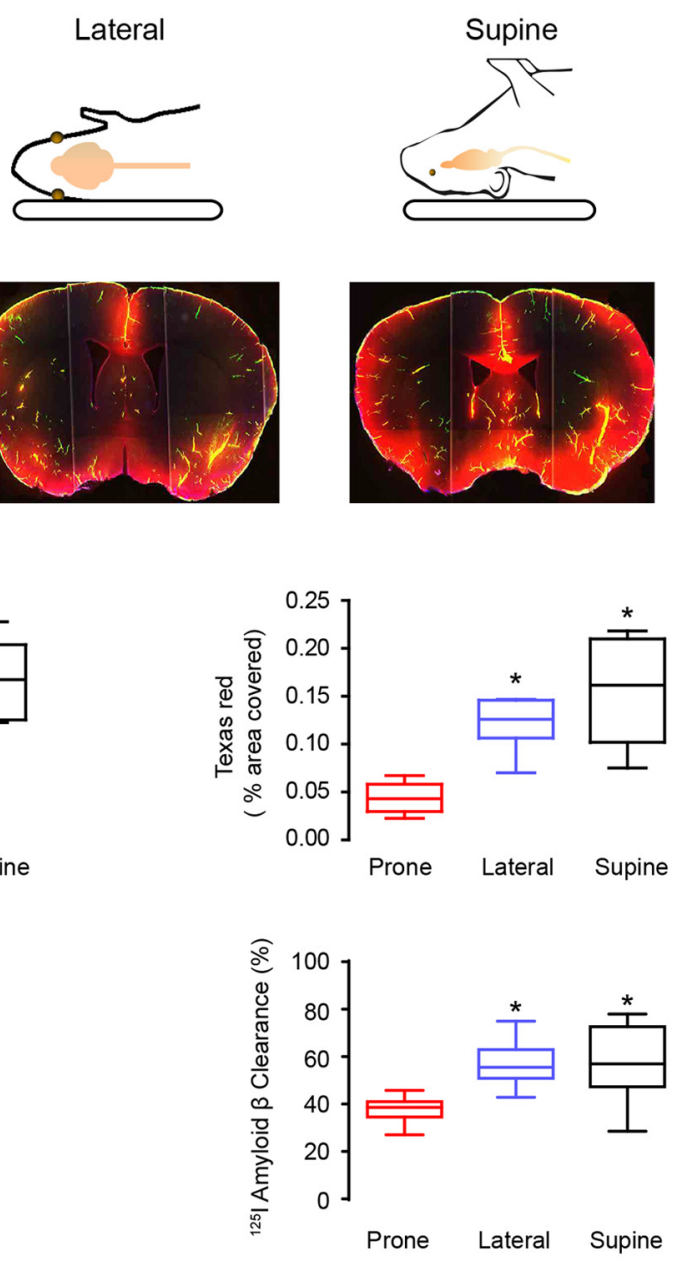

Merge - Texas red - 3KD FITC - 2000KD
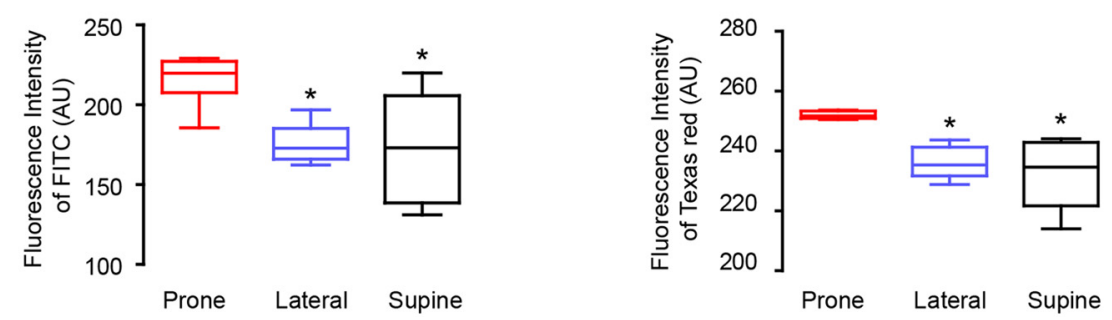

Figure 6. Effect of posture on glymphatic transport using fluorescent and radiolabeled tracers. $\boldsymbol{A}$, Small MW (Texas Redconjugated dextran, $3 \mathrm{kDa}$ ) and large MW tracer (FITC-conjugated dextran, $2000 \mathrm{kDa}$ ) were injected intracisternally in mice placed in the prone, lateral, and supine position. $\boldsymbol{B}$, Thirty minutes after injection, animals were perfusion fixed and whole-slice fluorescence was evaluated. Representative coronal sections are shown. CSF tracer influx in brain was significantly reduced in prone brain compared with lateral and supine brain ( ${ }^{*} p<0.05$, one-way ANOVA; for prone, $n=8$, for lateral and supine, $n=6$ ). $\boldsymbol{C}$, Radiolabeled ${ }^{125}$-amyloid $\beta 1-40$ was injected into cortex in mice in the same positions. Thirty minutes after injection, radiolabeled clearance was evaluated by gamma counting. ${ }^{125} \mathrm{I}-\mathrm{A} \beta 1-40$ clearance was significantly more efficient in the supine than in the lateral and prone positions ( ${ }^{*} p<0.05$; one-way ANOVA; for prone, $n=6$; for lateral and supine, $n=7$ ). $\boldsymbol{D}$, Fluorescent tracer

tone (Cifuentes et al., 1992; Rodríguez et al., 1999). It is interesting that we found the highest variability in glymphatic activity in the prone position, suggesting that a fraction of the animals adapted poorly to being placed in the prone position. Because the prone position is a natural position during wakefulness for rodents, it is unlikely that the suppression of glymphatic activity observed in this particular body position is an experimental artifact.

Although there are some anesthetics (e.g., urethane) that do not suppress the "rapid-eye-movement" (REM) component of sleep (Pagliardini et al., 2013), loss of consciousness during anesthesia is not the same as deep sleep and most clinically relevant anesthetics are REM suppressants (Power et al., 1998; Vazquez and Baghdoyan, 2004; Mashour et al., 2010). In addition, changes in the "default mode network" (DMN) as defined by functional MRI (or PET) differ between the various sleep stages across species. For example, during light sleep (humans), the DMN and the external control networks are intact (Horovitz et al., 2008; Larson-Prior et al., 2009), whereas, during deep, nonREM sleep, the posterior cingulate cortex and precuneus disconnect (Horovitz et al., 2009). During anesthesia, activity in the entire DMN is reduced and a change in "connectivity" occurs to also include motor/somatosensory cortices, the reticular activating system, and thalamic nuclei (Martuzzi et al., 2010). In other words, a limitation of our study is that the "stage of unconsciousness" induced by the anesthetic regimen does not include the complexity of the sleep stages during a night's sleep.

It is also important to emphasize that obvious differences in anatomical, physiological, and overall body dimensions between man and rat necessitate that our studies are critically tested in human subjects. Nevertheless, our study suggests that glymphatic transport is the most efficient when resting in the lateral position. MRI analysis showed that the reduced uptake of Gd-DTPA in the brain of prone rats was paralleled by increased efflux of CSF along the cervical vasculature. Imaging of fluorescently tagged CSF tracers in mice revealed that the prone position also was linked to reduced CSF influx in brain,

$\longleftarrow$

intensity was significantly higher in prone spinal cord compared with lateral and supine spinal cord. $\left({ }^{*} p<0.05\right.$, oneway ANOVA; for prone, $n=6$; for lateral, $n=5$; and for supine, $n=6$ ). 
Table 3. Comparison of parameters from TSCs derived from CSF efflux pathways

\begin{tabular}{|c|c|c|c|c|c|c|c|c|}
\hline \multirow[b]{2}{*}{ Exits } & \multirow[b]{2}{*}{ Parameter } & \multicolumn{2}{|c|}{ Prone $(n=7)$} & \multicolumn{2}{|c|}{ Supine $(n=9)$} & \multicolumn{2}{|c|}{$\operatorname{RLD}(n=8)$} & \multirow[b]{2}{*}{$p$-value } \\
\hline & & Mean & SD & Mean & SD & Mean & SD & \\
\hline \multirow[t]{2}{*}{ Along superior sagittal sinus } & $\mathrm{AUC}_{0-120}(\%$ signal change from baseline $* 120 \mathrm{~min})$ & 3406 & 2594 & 2259 & 1661 & 3251 & 1368 & 0.423 \\
\hline & Peak (\% signal change from baseline) & 57 & 41 & 38 & 22 & 55 & 24 & 0.368 \\
\hline \multirow[t]{2}{*}{ Acoustic (VIII) cranial nerve and cochlea } & $\mathrm{AUC}_{0-120}(\%$ signal change from baseline $* 120 \mathrm{~min})$ & 3483 & 868 & 3344 & 1010 & 4072 & 1126 & 0.323 \\
\hline & Peak (\% signal change from baseline) & 52 & 12 & 53 & 11 & 59 & 12 & 0.429 \\
\hline \multirow[t]{2}{*}{ Vagus $(X)$ cranial nerve } & $\mathrm{AUC}_{0-120}(\%$ signal change from baseline $* 120 \mathrm{~min})$ & 15170 & 5398 & 12891 & 4307 & 14989 & 6638 & 0.645 \\
\hline & Peak (\% signal change from baseline) & 263 & 108 & 177 & 66 & 214 & 93 & 0.181 \\
\hline \multirow[t]{2}{*}{ Along internal carotid artery } & $\mathrm{AUC}_{0-120}\left(\%\right.$ signal change from baseline $\left.{ }^{*} 120 \mathrm{~min}\right)$ & 6132 & 3924 & 2194 & 958 & 2934 & 1765 & 0.069 \\
\hline & Peak (\% signal change from baseline) & 148 & 86 & 54 & 26 & 77 & 47 & 0.049 \\
\hline
\end{tabular}

One-way ANOVA was used to investigate whether the AUC ${ }_{0-120}$, a parameter representing "efflux" via anatomical key exits points, and "peak" magnitudes were different between the three positional groups. Welch's ANOVA was used if the variance homogeneity condition did not hold. $p<0.05$ was considered statistically significant.

whereas the influx of fluorescent tracers into spinal cord was increased. We suspect that head position affects the activity of the glymphatic system similarly in rats and mice, but the difference in approach (MRI vs optical imaging) did not allow a formal species comparison. However, both sets of observations suggest that the lateral position during sleep has a clear advantage with regard to glymphatic removal of $\mathrm{A} \beta$ and other metabolic waste products of neural activity. Although this is speculative and awaits testing in human subjects, other clinical studies have shown that $\mathrm{A} \beta$ content in CSF is lower in sleep than wakefulness, consistent with increased clearance (Kang et al., 2009). Our analysis therefore suggests that the position of the head is an important factor to consider in future diagnostic tests of glymphatic activity. Furthermore, radionuclide cisternography, a diagnostic procedure that involves the administration of radionuclides into the lumbar intrathecal space, has been used in the clinical setting to help diagnose normal pressure hydrocephalus (NPH) and benign intraventricular hypertension (Børgesen et al., 1981). However, radionuclide cisternography has not been effective in predicting outcomes from shunt surgery in NPH (Hebb and Cusimano, 2001) and we speculate that one possibility for this lack of specificity is that the patient's sleep quality and/or sleep position is not taken into account during the $2-3 \mathrm{~d}$ of testing involved in this procedure.

\section{References}

Børgesen SE, Westergård L, Gjerris F (1981) Isotope cisternography and conductance to outflow of CSF in normal pressure hydrocephalus. Acta Neurochirurgica 57:67-73. CrossRef Medline

Brightman MW (1965a) The distribution within the brain of ferritin injected into cerebrospinal fluid compartments. II. Parenchymal distribution. Am J Anat 117:193-219. CrossRef Medline

Brightman MW (1965b) The distribution within the brain of ferritin injected into cerebrospinal fluid compartments. I. Ependymal distribution. J Cell Biol 26:99-123. CrossRef Medline

Brosnan RJ, Steffey EP, LeCouteur RA, Imai A, Farver TB, Kortz GD (2002) Effects of body position on intracranial and cerebral perfusion pressures in isoflurane-anesthetized horses. J Appl Physiol 92:2542-2546. CrossRef Medline

Bushey D, Tononi G, Cirelli C (2011) Sleep and synaptic homeostasis: structural evidence in Drosophila. Science 332:1576-1581. CrossRef Medline

Cifuentes M, Fernández-LLebrez P, Pérez J, Pérez-Fígares JM, Rodríguez EM (1992) Distribution of intraventricularly injected horseradish peroxidase in cerebrospinal fluid compartments of the rat spinal cord. Cell Tissue Res 270:485-494. CrossRef Medline

Cirelli C, Tononi G (2015) Sleep and synaptic homeostasis. Sleep 38:161162. Medline

Czosnyka M, Richards HK, Whitehouse HE, Pickard JD (1996) Relationship between transcranial Doppler-determined pulsatility index and cerebrovascular resistance: an experimental study. J Neurosurg 84:79-84. CrossRef Medline

Datta S, Hobson JA (2000) The rat as an experimental model for sleep neurophysiology. Behav Neurosci 114:1239-1244. CrossRef Medline
De Koninck J, Gagnon P, Lallier S (1983) Sleep positions in the young adult and their relationship with the subjective quality of sleep. Sleep 6:52-59. Medline

De Koninck J, Lorrain D, Gagnon P (1992) Sleep positions and position shifts in five age groups: an ontogenetic picture. Sleep 15:143-149. Medline

Dreha-Kulaczewski S, Joseph AA, Merboldt KD, Ludwig HC, Gärtner J, Frahm J (2015) Inspiration is the major regulator of human CSF flow. J Neurosci 35:2485-2491. CrossRef Medline

Dwyer T, Ponsonby AL (2009) Sudden infant death syndrome and prone sleeping position. Ann Epidemiol 19:245-249. CrossRef Medline

Grant R, Condon B, Patterson J, Wyper DJ, Hadley MD, Teasdale GM (1989) Changes in cranial CSF volume during hypercapnia and hypocapnia. J Neurol Neurosurg Psychiatry 52:218-222. CrossRef Medline

Grubb RL Jr, Raichle ME, Eichling JO, Ter-Pogossian MM (1974) The effects of changes in $\mathrm{PaCO} 2$ on cerebral blood volume, blood flow, and vascular mean transit time. Stroke 5:630-639. CrossRef Medline

Hebb AO, Cusimano MD (2001) Idiopathic normal pressure hydrocephalus: a systematic review of diagnosis and outcome. Neurosurgery 49: 1166-1184; discussion 1184-1166.

Horovitz SG, Fukunaga M, de Zwart JA, van Gelderen P, Fulton SC, Balkin TJ, Duyn JH (2008) Low frequency BOLD fluctuations during resting wakefulness and light sleep: a simultaneous EEG-fMRI study. Hum Brain Mapp 29:671-682. CrossRef Medline

Horovitz SG, Braun AR, Carr WS, Picchioni D, Balkin TJ, Fukunaga M, Duyn JH (2009) Decoupling of the brain's default mode network during deep sleep. Proc Natl Acad Sci U S A 106:11376-11381. CrossRef Medline

Iliff JJ, Wang M, Liao Y, Plogg BA, Peng W, Gundersen GA, Benveniste H, Vates GE, Deane R, Goldman SA, Nagelhus EA, Nedergaard M (2012) A paravascular pathway facilitates CSF flow through the brain parenchyma and the clearance of interstitial solutes, including amyloid beta. Sci Trans Med 4:147ra111. Medline

Iliff JJ, Lee H, Yu M, Feng T, Logan J, Nedergaard M, Benveniste H (2013a) Brainwide pathway for waste clearance captured by contrast-enhanced MRI. J Clin Invest 123:1299-1309. CrossRef Medline

Iliff JJ, Wang M, Zeppenfeld DM, Venkataraman A, Plog BA, Liao Y, Deane R, Nedergaard M (2013b) Cerebral arterial pulsation drives paravascular CSF-interstitial fluid exchange in the murine brain. J Neurosci 33:1819018199. CrossRef Medline

Kang JE, Lim MM, Bateman RJ, Lee JJ, Smyth LP, Cirrito JR, Fujiki N, Nishino S, Holtzman DM (2009) Amyloid-beta dynamics are regulated by orexin and the sleep-wake cycle. Science 326:1005-1007. CrossRef Medline

Koeppe RA, Holthoff VA, Frey KA, Kilbourn MR, Kuhl DE (1991) Compartmental analysis of [11C]flumazenil kinetics for the estimation of ligand transport rate and receptor distribution using positron emission tomography. J Cereb Blood Flow Metab 11:735-744. CrossRef Medline

Kose G, Hatipoglu S (2012) Effect of head and body positioning on cerebral blood flow velocity in patients who underwent cranial surgery. J Clin Nurs 21:1859-1867. CrossRef Medline

Kress BT, Iliff JJ, Xia M, Wang M, Wei HS, Zeppenfeld D, Xie L, Kang H, Xu Q, Liew JA, Plog BA, Ding F, Deane R, Nedergaard M (2014) Impairment of paravascular clearance pathways in the aging brain. Ann Neurol 76:845-861. CrossRef Medline

Kuo CD, Chen GY, Lo HM (2000) Effect of different recumbent positions on spectral indices of autonomic modulation of the heart during the acute 
phase of myocardial infarction. Crit Care Med 28:1283-1289. CrossRef Medline

Larson-Prior LJ, Zempel JM, Nolan TS, Prior FW, Snyder AZ, Raichle ME (2009) Cortical network functional connectivity in the descent to sleep. Proc Natl Acad Sci U S A 106:4489-4494. CrossRef Medline

Logan J, Fowler JS, Volkow ND, Wolf AP, Dewey SL, Schlyer DJ, MacGregor RR, Hitzemann R, Bendriem B, Gatley SJ (1990) Graphical analysis of reversible radioligand binding from time-activity measurements applied to [N-11C-methyl]-(-)-cocaine PET studies in human subjects. J Cereb Blood Flow Metab 10:740-747. CrossRef Medline

Logan J, Fowler JS, Volkow ND, Ding YS, Wang GJ, Alexoff DL (2001) A strategy for removing the bias in the graphical analysis method. J Cereb Blood Flow Metab 21:307-320. Medline

Martin-Du Pan RC, Benoit R, Girardier L (2004) The role of body position and gravity in the symptoms and treatment of various medical diseases. Swiss medical weekly 134:543-551. Medline

Martuzzi R, Ramani R, Qiu M, Rajeevan N, Constable RT (2010) Functional connectivity and alterations in baseline brain state in humans. Neuroimage 49:823-834. CrossRef Medline

Mashour GA, Lipinski WJ, Matlen LB, Walker AJ, Turner AM, Schoen W, Lee U, Poe GR (2010) Isoflurane anesthesia does not satisfy the homeostatic need for rapid eye movement sleep. Anesth Analg 110:1283-1289. CrossRef Medline

Mignini F, Sabbatini M, Coppola L, Cavallotti C (2012) Analysis of nerve supply pattern in human lymphatic vessels of young and old men. Lymphatic Res Biol 10:189-197. CrossRef Medline

Nedergaard M (2013) Neuroscience. Garbage truck of the brain. Science 340:1529-1530. CrossRef Medline

Newell DW, Weber JP, Watson R, Aaslid R, Winn HR (1996) Effect of transient moderate hyperventilation on dynamic cerebral autoregulation after severe head injury. Neurosurgery 39:35-43; discussion 43-34.

Pagliardini S, Gosgnach S, Dickson CT (2013) Spontaneous sleep-like brain state alternations and breathing characteristics in urethane anesthetized mice. PLoS One 8:e70411. CrossRef Medline

Plog BA, Dashnaw ML, Hitomi E, Peng W, Liao Y, Lou N, Deane R, Nedergaard M (2015) Biomarkers of traumatic injury are transported from brain to blood via the glymphatic system. J Neurosci 35:518-526. CrossRef Medline

Power C, Crowe C, Higgins P, Moriarty DC (1998) Anaesthetic depth at induction: an evaluation using clinical eye signs and EEG polysomnography. Anaesthesia 53:736-743. CrossRef Medline
Rehder K (1998) Postural changes in respiratory function. Acta Anaesthesiol Scand Suppl 113:13-16. Medline

Rescigno A, Bocchialini BM (1991) From pharmacokinetics: unfolding of a concept. In: New Trends in Pharmacokinetics (Rescigno A, Thakur A, eds), pp 1-25. New York: Plenum.

Rodríguez S, Vio K, Wagner C, Barría M, Navarrete EH, Ramírez VD, PérezFígares JM, Rodríguez EM (1999) Changes in the cerebrospinal-fluid monoamines in rats with an immunoneutralization of the subcommissural organ-Reissner's fiber complex by maternal delivery of antibodies. Exp Brain Res 128:278-290. CrossRef Medline

Schneider GH, von Helden GH, Franke R, Lanksch WR, Unterberg A (1993) Influence of body position on jugular venous oxygen saturation, intracranial pressure and cerebral perfusion pressure. Acta Neurochir Suppl (Wien) 59:107-112. Medline

Schneider GH, Sarrafzadeh AS, Kiening KL, Bardt TF, Unterberg AW, Lanksch WR (1998) Influence of hyperventilation on brain tissue-PO2, $\mathrm{PCO} 2$, and $\mathrm{pH}$ in patients with intracranial hypertension. Acta Neurochir Suppl 71:62-65. Medline

Schwenke DO, Cragg PA (2004) Comparison of the depressive effects of four anesthetic regimens on ventilatory and cardiovascular variables in the guinea pig. Comp Med 54:77-85. Medline

Tobler I (1992) Behavioral sleep in the Asian elephant in captivity. Sleep 15:1-12. Medline

Tofts PS (1997) Modeling tracer kinetics in dynamic Gd-DTPA MR imaging. J Magn Reson Imaging 7:91-101. CrossRef Medline

van Kesteren ER, van Maanen JP, Hilgevoord AA, Laman DM, de Vries N (2011) Quantitative effects of trunk and head position on the apnea hypopnea index in obstructive sleep apnea. Sleep 34:1075-1081. Medline

Vazquez J, Baghdoyan HA (2004) GABAA receptors inhibit acetylcholine release in cat pontine reticular formation: implications for REM sleep regulation. J Neurophysiol 92:2198-2206. CrossRef Medline

Xie L, Kang H, Xu Q, Chen MJ, Liao Y, Thiyagarajan M, O’Donnell J, Christensen DJ, Nicholson C, Iliff JJ, Takano T, Deane R, Nedergaard M (2013) Sleep drives metabolite clearance from the adult brain. Science 342:373-377. CrossRef Medline

Yang L, Kress BT, Weber HJ, Thiyagarajan M, Wang B, Deane R, Benveniste H, Iliff JJ, Nedergaard M (2013) Evaluating glymphatic pathway function using clinically relevant intrathecal infusion of CSF tracer. J Transl Med 11:107. CrossRef Medline 